\title{
Growth Models and Projection of Area, Production and Productivity of Wheat in India and Uttar Pradesh, India
}

\author{
Manvendra Singh" and K. Supriya \\ Department of Statistics and Mathematics, College of Agriculture, ANGRAU, \\ Rajendranagar, Hyderabad, Telangana, India \\ *Corresponding author
}

\section{A B S T R A C T}

K e y w o r d s
Wheat, Linear Growth
Rate (LGR),
Compound Growth
Rate (CGR),
Statistical models,
Future projections.
Article Info
Accepted:
$\begin{aligned} & \text { 20 September } 2017 \\ & \text { Available Online: } \\ & 10 \text { November } 2017\end{aligned}$

\section{Keywords}

Wheat, Linear Growth

Rate (CGR),

Article Info

Accepted:

Available Online:

10 November 2017
Wheat (Triticum aestivum L.) is one of the most important cereal crops in India and a main source of vitamins and minerals such as thiamine, niacin, iron, riboflavin, vitamin $\mathrm{D}$, calcium, and fiber. Wheat covers approximately $25 \%$ of the total global area devoted to by cereal crops. Since the consumption of wheat is directly proportional to the population growth. Feeding burgeoning population through the next 25 years remains an uphill task. Increasing domestic demand owing to population growth should meet the future challenges of food and nutritional security. On this prospective for the planning purposes decision to invest accordingly for the short and long-term plans, the present study has been undertaken to evaluate the growth in area, production and productivity of Wheat crop in India by using different growth models. Linear, logarithmic, Inverse, Quadratic, Cubic, Power, compound, Sigmoid, Growth, and Exponential models have been used to find out the best relationship. Adj. $\mathrm{R}^{2}$ value has been used for selecting the best fitted model.

\section{Introduction}

Wheat (Triticum aestivum L.) is an important cereal crop in the world under a varied range of climatic conditions. In India, Wheat is grown from $11^{\circ} \mathrm{N}$ to $30^{\circ} \mathrm{N}$ latitude and from sea level up to elevation of $3658 \mathrm{~m}$ in the Himalayas. It is grown in a wide range of temperature and annual rainfall, from sandy loam soil to heavy black cotton clay soils (Chatterji 1966).

Wheat is the excellent source of carbohydrates, energy and has no fat. It is also a good source of vitamins and minerals such as thiamine, niacin, iron, riboflavin, vitamin $\mathrm{D}$, calcium, and fiber. In India Wheat is cultivated under wide range of agro-climatic conditions from Kashmir and other mountainous region as well as wet soils in the deltaic coastal areas to arid soils in Rajasthan. It is also grown in the coastal sandy regions in some of the hilly tracts of north. The pace of wheat production has to be maintained accordingly due to fast increasing population of the country (Singh et al., 2003). Over 3000 varieties are under cultivation in different parts of the country and these varieties differ 
in their duration, grain quality and other plant characters viz., water requirement, response to fertilizers, resistance to diseases, drought, alkalinity and salinity etc. the cultivation practices adopted in different part of the country differs as per the agro climatic zones.

India occupies $2^{\text {nd }}$ position in the World Wheat production. In India, Wheat was grown all over the country with an area of 30 million hectares, production of 93.2 million tones and with the productivity of $2980 \mathrm{~kg} / \mathrm{ha}$ during 2010-11 (Anonymous, 2013).

Keeping in view of the above discussion, the present study has been undertaken to evaluate the growth in area, production and productivity of Wheat crop in India by using different growth models. Yoginder et al., (1980) aimed at studying the growth rates of crops for the periods of green revolution (period I: 1960-61 to 1969-70) and post-green revolution (period II: $1970-71$ to $1978-79$ ).

Singh et al., (1997) studied the trend in area, production and yield of wheat at the state level in India and the factors responsible for determining yield and acreage of important food grain crops.

This study has been undertaken to throw light on the policy decision to invest accordingly for the short and long-term plans and also to provide a direction of research which would bring sustainable development in agriculture.

\section{Materials and Methods}

The time series secondary data of area, production and productivity of selected of wheat crop in India at in million hectare, million ton, kilogram/hectare from 1971 to 2010 are extracted from the from the publications of Centre for Monitoring Indian Economy (CMIE), Mumbai (Figs. 1, 2, 3 4, 5 and 6).

\section{Estimation of growth rate}

Linear growth rate (LGR) and compound growth rate (CGR) were used for the estimation of growth rates in crop characteristics i.e., area, production and productivity of Wheat crop in India.

\section{Linear function}

Linear function is given by the equation:

$\mathrm{Y}=\mathrm{a}+\mathrm{bt}$

Where,

$\mathrm{t}$ is the time in years, independent variable $\mathrm{Y}$ is the trend value of the dependent variable $\mathrm{a}$ and $\mathrm{b}$ are constants

The above equation is fitted by using the least squares method of estimation.

The linear growth rate is calculated by the formula:

Linear growth rate $($ LGR $\%)=\frac{\mathrm{b}}{\bar{y}} \times 100$

\section{Compound function}

Compound function is given by the equation:

$Y=a b^{t}$ or $\log y=\log a+t \log b$

Where,

$\mathrm{t}$ is the time in years, independent variable

$\mathrm{y}$ is the characteristic (area, production or productivity of dependent variable)

$\mathrm{a}$ and $\mathrm{b}$ are parameters

The ' $a$ ' and ' $b$ ' are calculated by applying the method of Least Squares. 
The compound growth rate: CGR $(\%)=(\mathrm{b}-1)$ $\mathrm{x} 100$

\section{Fitting the trend equations}

The trend equations were fitted by using different growth models. Growth models are nothing but the models that describe the behavior of a variable overtime. Linear, logarithmic, Inverse, Quadratic, Cubic, Power, Sigmoid, Growth, and Exponential models have been used in the present study.

Fitting of Different Growth Models to area, production and productivity Wheat of crop in India

Area of Wheat in India showed a constant growth pattern in the study period of 1971 to 2010. The results obtained by fitting all the ten growth models were presented in Table 2 . Adj $R^{2}$ values for all the models were 0.895 for linear function, 0.893 for logarithmic function, 0.405 for inverse function, 0.902 for quadratic function, 0.911 for cubic function, 0.875 for compound function, 0.858 for power function, 0.438 for S- curve, 0.873 for growth function, and 0.873 for exponential function, respectively. All the models Adj $\mathrm{R}^{2}$ values were significant at $1 \%$ level of significance. Cubic model was found to be the best for estimation of area of wheat in India with higher $\mathrm{Adj}^{2}$ value 0.911 .

\section{Fitting of different growth models to production}

The Production of Wheat in India showed a systematic growth pattern during the study period of 1971 to 2010 . The results obtained by fitting all the ten growth models were presented in Table 3. Adj $\mathrm{R}^{2}$ values among all the models were 0.962 for linear function, 0.819 for logarithmic function, 0.332 for inverse function, 0.966 for quadratic function, 0.966 for cubic function, 0.925 for compound function, 0.888 for power function, 0.411 for S- curve, 0.925 for growth function, and 0.925 for exponential function, respectively. In all the models, Adj $\mathrm{R}^{2}$ values were significant at $1 \%$ level of significance. Cubic model was found to be the best for estimation of area of wheat in India with higher $\operatorname{Adj}^{2}$ value 0.966 .

\section{Fitting of Different Growth Models to productivity}

The Productivity of Wheat in India showed an increasing trend during the study period of 1971 to 2010. The results obtained by fitting all the ten growth models were presented in Table 4. Adj $R^{2}$ values for all the models were 0.944 for linear function, 0.834 for logarithmic function, 0.342 for inverse function, 0.964 for quadratic function, 0.969 for cubic function, 0.914 for compound function, 0.869 for power function, 0.384 for S- curve, 0.914 for growth function, and 0.914 for exponential function, respectively. In all the models, Adj $\mathrm{R}^{2}$ values were significant at $1 \%$ level of significance. Cubic model was found to be the best for estimation of area of wheat in India with higher $\operatorname{Adj}^{2}$ value 0.969 .

Fitting of different growth models to area, production and productivity wheat of crop in Uttar Pradesh

\section{Fitting of different growth models to area}

Area of Wheat in Uttar Pradesh showed a constant growth pattern in the study period of 1971 to 2010 . The results obtained by fitting all the ten growth models were presented in Table 5. Adj $\mathrm{R}^{2}$ values for all the models were 0.814 for linear function, 0.918 for logarithmic function, 0.52 for inverse function, 0.945 for quadratic function, 0.959 for cubic function, 0.777 for compound function, 0.919 for power function, 0.777 for 
S- curve, 0.873 for growth function, and 0.777 for exponential function, respectively. All the models Adj $\mathrm{R}^{2}$ values were significant at $1 \%$ level of significance. Cubic model was found to be the best for estimation of area of wheat in Uttar Pradesh with higher $\mathrm{Adj}^{2}$ value 0.959 .

Fitting of different growth models to production

The Production of Wheat in Uttar Pradesh showed a systematic growth pattern during the study period of 1971 to 2010 . The results obtained by fitting all the ten growth models were presented in Table 6 . Adj $R^{2}$ values among all the models were 0.822 for linear function, 0.766 for logarithmic function, 0.467 for inverse function, 0.812 for quadratic function, 0.866 for cubic function, 0.824 for compound function, 0.803 for power function, 0.512 for S- curve, 0.824 for growth function, and 0.824 for exponential function, respectively. In all the models, Adj $\mathrm{R}^{2}$ values were significant at $1 \%$ level of significance. Cubic model was found to be the best for estimation of area of wheat in Uttar Pradesh with higher $\operatorname{Adj}^{2}$ value 0.866 .

Table.1 Expressions of model

\begin{tabular}{|l|l|c|}
\hline Sl.No. & Model & Expression \\
\hline $\mathbf{1}$ & Linear & $y=b_{0}+b_{1} x$ \\
\hline $\mathbf{2}$ & Logarithmic & $y=b_{0}+b_{1} \ln (x)$ \\
\hline $\mathbf{3}$ & Inverse & $y=b_{0}+\frac{b_{1}}{x}$ \\
\hline $\mathbf{4}$ & & $y=b_{0}+b_{1} x+b_{2} x^{2}$ \\
\hline $\mathbf{5}$ & Quadratic & $y=b_{0}+b_{1} x+b_{2} x^{2}+b_{3} x^{z}$ \\
\hline $\mathbf{6}$ & Cubic & $y=b_{0} b_{1}^{2}$ \\
\hline $\mathbf{7}$ & Compound & $y=b_{0} x^{b_{1}}$ \\
\hline $\mathbf{8}$ & Power & $y=\exp ^{b_{0}+\frac{b_{1}}{x}}$ \\
\hline $\mathbf{9}$ & Sigmoid (S) & $y=\exp ^{b_{0}+b_{1} x}$ \\
\hline $\mathbf{1 0}$ & Growth & $y=b_{0} \exp ^{b_{1} x}$ \\
\hline
\end{tabular}

Table.2 Growth models for the area of wheat in India

\begin{tabular}{|l|l|l|l|l|l|l|}
\hline Model & \multicolumn{1}{|c|}{$b_{0}$} & \multicolumn{1}{c|}{$b_{1}$} & \multicolumn{1}{c|}{$b_{2}$} & $b_{3}$ & $\mathbf{A d j R}^{2}$ & RMSE \\
\hline Linear & 19510.88 & 229.74 & & & $0.895^{* *}$ & 864.33 \\
\hline Logarithmic & 16007.83 & 2977.75 & & & $0.893^{* *}$ & 1325.52 \\
\hline Inverse & 25360.34 & -10656.13 & & & $0.405^{* *}$ & 4793.29 \\
\hline Quadratic & 18775.49 & 334.79 & -2.56 & & $0.902^{* *}$ & 787.06 \\
\hline Cubic & 17892.16 & 578.42 & -17.24 & 0.24 & $0.911^{* *}$ & 717.20 \\
\hline Compound & 19709.30 & 1.01 & & & $0.875^{* *}$ & 971.46 \\
\hline Power & 16855.32 & 0.13 & & & $0.858^{* *}$ & 1089.09 \\
\hline S- curve & 10.14 & -0.47 & & & $0.438^{* *}$ & 4435.12 \\
\hline Growth & 9.89 & 0.01 & & & $0.873^{* *}$ & 971.46 \\
\hline Exponential & 19709.30 & 0.01 & & & $0.873^{* *}$ & 971.46 \\
\hline
\end{tabular}


Table.3 Growth models for production of wheat in India

\begin{tabular}{|l|l|l|l|l|l|l|}
\hline Model & \multicolumn{1}{|c|}{$b_{\mathrm{c}}$} & \multicolumn{1}{c|}{$b_{1}$} & \multicolumn{1}{c|}{$b_{\overline{2}}$} & $b_{\Sigma}$ & AdjR $^{2}$ & RMSE \\
\hline Linear & 21639.123 & 1579.416 & & & $0.962^{* *}$ & 1335.44 \\
\hline Logarithmic & 95.795 & 19550.778 & & & $0.819^{* *}$ & 6400.30 \\
\hline Inverse & 60903.874 & -64383.802 & & & $0.332^{* *}$ & 23642.55 \\
\hline Quadratic & 18611.058 & 2011.997 & -10.551 & & $0.966^{* *}$ & 1200.92 \\
\hline Cubic & 20408.445 & 1516.275 & 19.306 & -0.485 & $0.966^{* *}$ & 1196.30 \\
\hline Compound & 25981.997 & 1.033 & & & $0.925^{* *}$ & 35.40 \\
\hline Power & 15634.555 & 0.425 & & & $0.888^{* *}$ & 28.68 \\
\hline S- curve & 10.987 & -1.485 & & & $0.411^{* *}$ & 208.04 \\
\hline Growth & 10.165 & 0.032 & & & $0.925^{* *}$ & 35.40 \\
\hline Exponential & 25981.997 & 0.032 & & & $0.925^{* *}$ & 35.40 \\
\hline
\end{tabular}

Table.4 Growth models for productivity of wheat in India

\begin{tabular}{|c|c|c|c|c|c|c|}
\hline Model & $b_{c}$ & $b_{1}$ & $b_{2}$ & $b_{\Sigma}$ & $\operatorname{Adj}^{2}$ & RMSE \\
\hline Linear & 1232.803 & 45.766 & & & $0.944 * *$ & 169.90 \\
\hline Logarithmic & 579.670 & 576.983 & & & $0.834 * *$ & 501.40 \\
\hline Inverse & 2375.091 & -1908.041 & & & $0.342 * *$ & 1993.88 \\
\hline Quadratic & 1044.012 & 72.736 & -0.658 & & $0.964 * *$ & 108.17 \\
\hline Cubic & 1165.890 & 39.122 & 1.367 & $-3.292 \mathrm{E}-02$ & $0.969 * *$ & 93.71 \\
\hline Compound & 1318.261 & 1.023 & & & $0.914 * *$ & 334.82 \\
\hline Power & 927.574 & .296 & & & $0.869 * *$ & 276.48 \\
\hline S- curve & 7.756 & -1.012 & & & $0.384 * *$ & 1777.59 \\
\hline Growth & 7.184 & .023 & & & $0.914 * *$ & 334.82 \\
\hline Exponential & 1318.261 & .023 & & & $0.914 * *$ & 334.82 \\
\hline
\end{tabular}

Table.5 Growth models for the area of wheat in Uttar Pradesh

\begin{tabular}{|c|r|r|r|r|r|r|}
\hline Model & \multicolumn{1}{c|}{$b_{0}$} & \multicolumn{1}{c|}{$b_{1}$} & \multicolumn{1}{c|}{$b_{2}$} & \multicolumn{1}{c|}{$b_{3}$} & \multicolumn{1}{c|}{$\operatorname{AdjR}^{2}$} & \multicolumn{1}{l|}{ RMSE } \\
\hline Linear & 6634.77 & 83.66 & & & $0.814^{* *}$ & 2251.48 \\
\hline Logarithmic & 5053.15 & 1195.28 & & & $0.918^{* *}$ & 991.59 \\
\hline Inverse & 8844.00 & -4620.81 & & & $0.52^{* *}$ & 5799.77 \\
\hline Quadratic & 5645.97 & 224.91 & -3.45 & & $0.945^{* *}$ & 660.35 \\
\hline Cubic & 5299.24 & 320.54 & -9.20 & 0.09 & $0.959^{* *}$ & 493.03 \\
\hline Compound & 6645.42 & 1.01 & & & $0.777^{* *}$ & 2923.49 \\
\hline Power & 5379.80 & 0.16 & & & $0.919 * *$ & 874.77 \\
\hline S- curve & 9.09 & -0.62 & & & $0.777^{* *}$ & 4852.11 \\
\hline Growth & 8.80 & 0.01 & & & $0.873^{* *}$ & 2923.49 \\
\hline Exponential & 6645.42 & 0.01 & & & $0.777^{* *}$ & 2923.49 \\
\hline
\end{tabular}


Table.6 Growth models for production of wheat in Uttar Pradesh

\begin{tabular}{|l|r|r|r|r|r|r|}
\hline Model & \multicolumn{1}{|c|}{$b_{0}$} & \multicolumn{1}{c|}{$b_{1}$} & \multicolumn{1}{c|}{$b_{2}$} & \multicolumn{1}{c|}{$b_{3}$} & \multicolumn{1}{c|}{$\operatorname{AdjR}^{2}$} & \multicolumn{1}{l|}{ RMSE } \\
\hline Linear & 20171.20 & 408.69 & & & $0.822^{* *}$ & 1255.61 \\
\hline Logarithmic & 18367.87 & 2879.16 & & & $0.766^{* *}$ & 1646.81 \\
\hline Inverse & 25964.83 & -8351.98 & & & $0.467 * *$ & 3748.68 \\
\hline Quadratic & 19929.78 & 474.53 & -3.14 & & $0.812^{* *}$ & 1319.32 \\
\hline Cubic & 17758.10 & 1582.64 & -131.89 & 4.09 & $0.866^{* *}$ & 940.98 \\
\hline Compound & 20375.89 & 1.02 & & & $0.824^{* *}$ & 1285.47 \\
\hline Power & 18816.65 & 0.12 & & & $0.803^{* *}$ & 1505.17 \\
\hline S- curve & 10.16 & -0.36 & & & $0.512^{* *}$ & 3515.67 \\
\hline Growth & 9.92 & 0.02 & & & $0.824^{* *}$ & 1285.47 \\
\hline Exponential & 20375.89 & 0.02 & & & $0.824 * *$ & 1285.47 \\
\hline
\end{tabular}

Table.7 Growth models for productivity of wheat in Uttar Pradesh

\begin{tabular}{|c|r|r|r|r|r|r|}
\hline Model & \multicolumn{1}{|c|}{$b_{0}$} & \multicolumn{1}{c|}{$b_{1}$} & \multicolumn{1}{c|}{$b_{2}$} & $b_{3}$ & \multicolumn{1}{c|}{ AdjR $^{2}$} & \multicolumn{1}{l|}{ RMSE } \\
\hline Linear & 1089.036 & 53.581 & & & $0.944^{* *}$ & 424.23 \\
\hline Logarithmic & 352.138 & 665.447 & & & $0.834^{* *}$ & 984.33 \\
\hline Inverse & 2422.409 & -2196.622 & & & $0.314^{* *}$ & 2974.87 \\
\hline Quadratic & 973.622 & 70.069 & -.402 & & $0.905^{* *}$ & 410.91 \\
\hline Cubic & 1053.389 & 48.069 & 0.923 & $-2.155 \mathrm{E}-02$ & $0.904^{* *}$ & 414.85 \\
\hline Compound & 1215.730 & 1.027 & & & $0.899^{* *}$ & 609.06 \\
\hline Power & 808.654 & 0.343 & & & $0.854^{* *}$ & 636.01 \\
\hline S- curve & 7.770 & -1.190 & & & $0.387^{* *}$ & 2676.77 \\
\hline Growth & 7.103 & 0.026 & & & $0.899^{* *}$ & 609.06 \\
\hline Exponential & 1215.730 & 0.026 & & & $0.899^{* *}$ & 609.06 \\
\hline
\end{tabular}

Table.8 Projections of area, production and productivity wheat in India

\begin{tabular}{|c|r|r|r|}
\hline Year & Area ('000 ha) & Production ('000 tonnes) & Productivity (kg/ha) \\
\hline $2010-11$ & 27204.383 & 81570 & 2798.52862 \\
\hline $2011-12$ & 27289.021 & 82180 & 2780.99492 \\
\hline $2012-13$ & 27371.923 & 82706 & 2757.89899 \\
\hline $2013-14$ & 27453.161 & 83146 & 2729.04333 \\
\hline $2014-15$ & 27532.807 & 83497 & 2694.23041 \\
\hline $2015-16$ & 27610.925 & 83754 & 2653.26272 \\
\hline
\end{tabular}

Table.9 Projections of area, production and productivity wheat in Uttar Pradesh

\begin{tabular}{|c|r|r|r|}
\hline Year & Area ('000 ha) & Production ('000 tonnes) & Productivity (kg/ha) \\
\hline $2010-11$ & 9422.643366 & 30683.87818 & 3170.450171 \\
\hline $2011-12$ & 9463.079657 & 32264.54261 & 3207.141506 \\
\hline $2012-13$ & 9508.706512 & 34120.97164 & 3243.028563 \\
\hline $2013-14$ & 9560.085848 & 36277.6901 & 3278.111343 \\
\hline $2014-15$ & 9617.77958 & 38759.22279 & 3312.389844 \\
\hline $2015-16$ & 9682.349622 & 41590.09454 & 3345.864068 \\
\hline
\end{tabular}


Fig.1 Time series data of total wheat area (Million hac) of Uttar Pradesh from 1971 to 2010

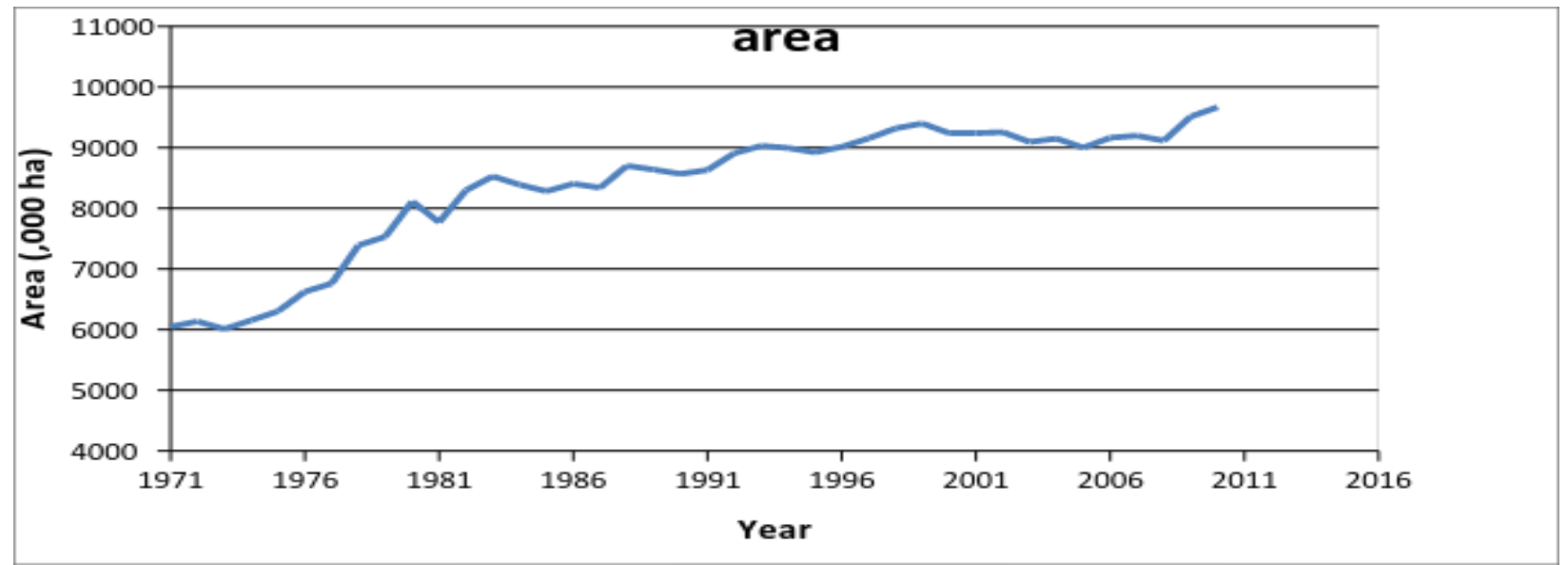

Fig.2 Time series data of total wheat production (Million ton) of Uttar Pradesh from 1971 to 2010

\section{Production}

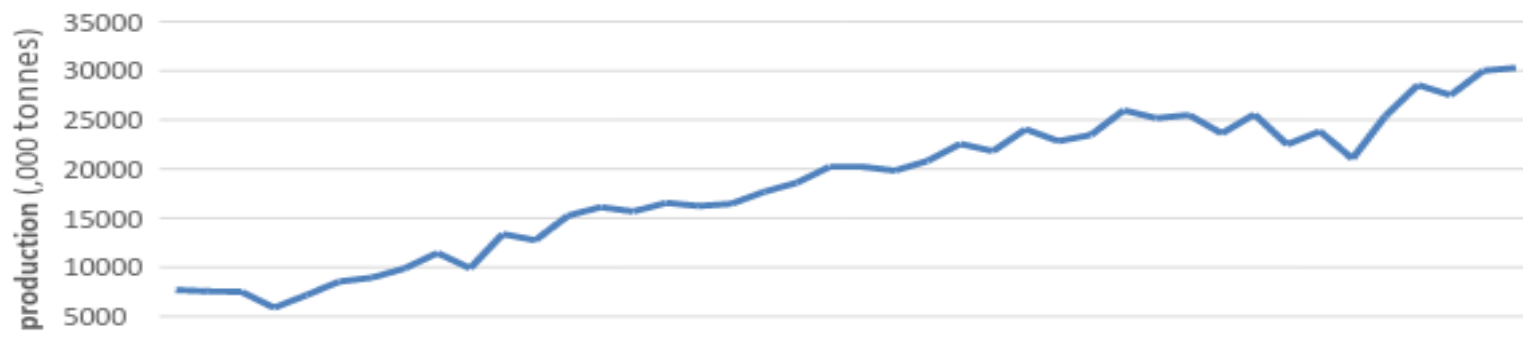

0

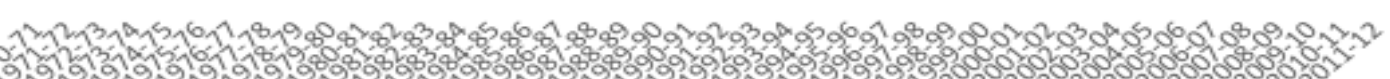
की की

Axis Title

Fig.3 Time series data of total wheat productivity (Kg/ha) of Uttar Pradesh from 1971 to 2010

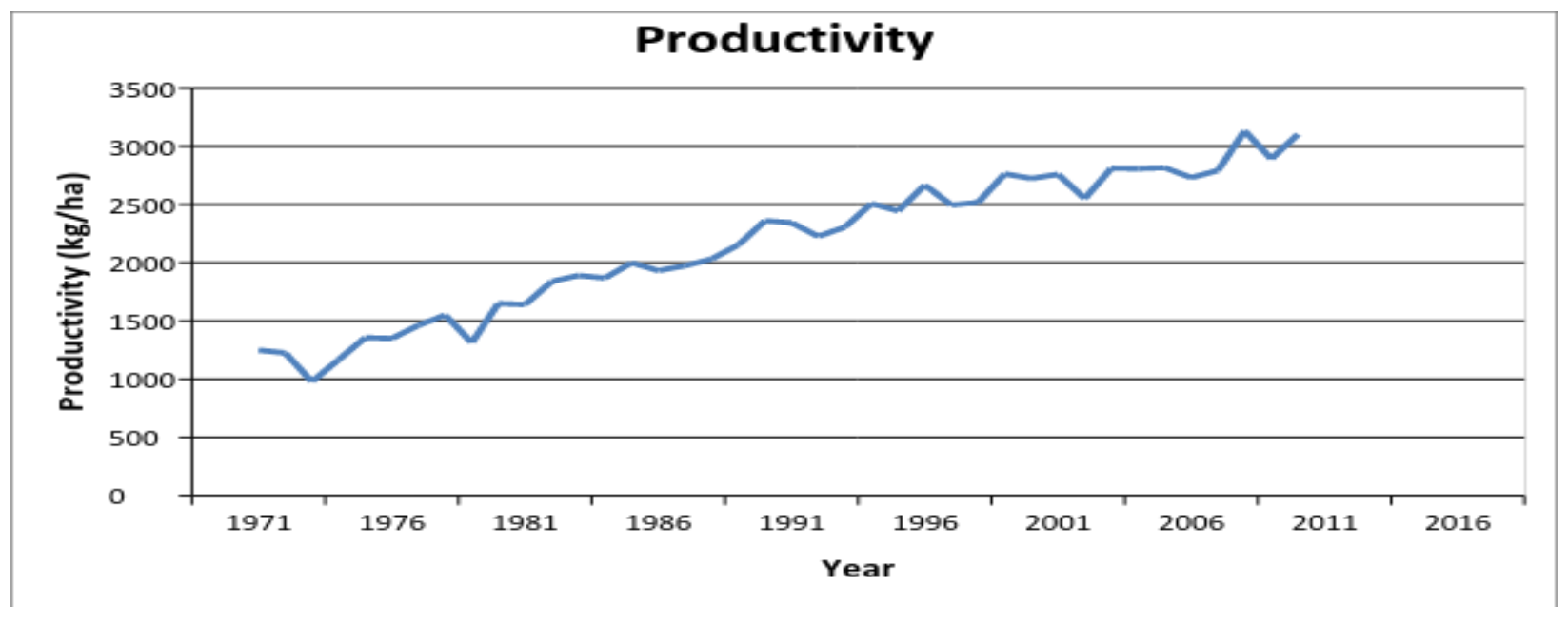


Fig.4 Time series data of total wheat cultivated area (million hectare) of India from 1971 to 2010

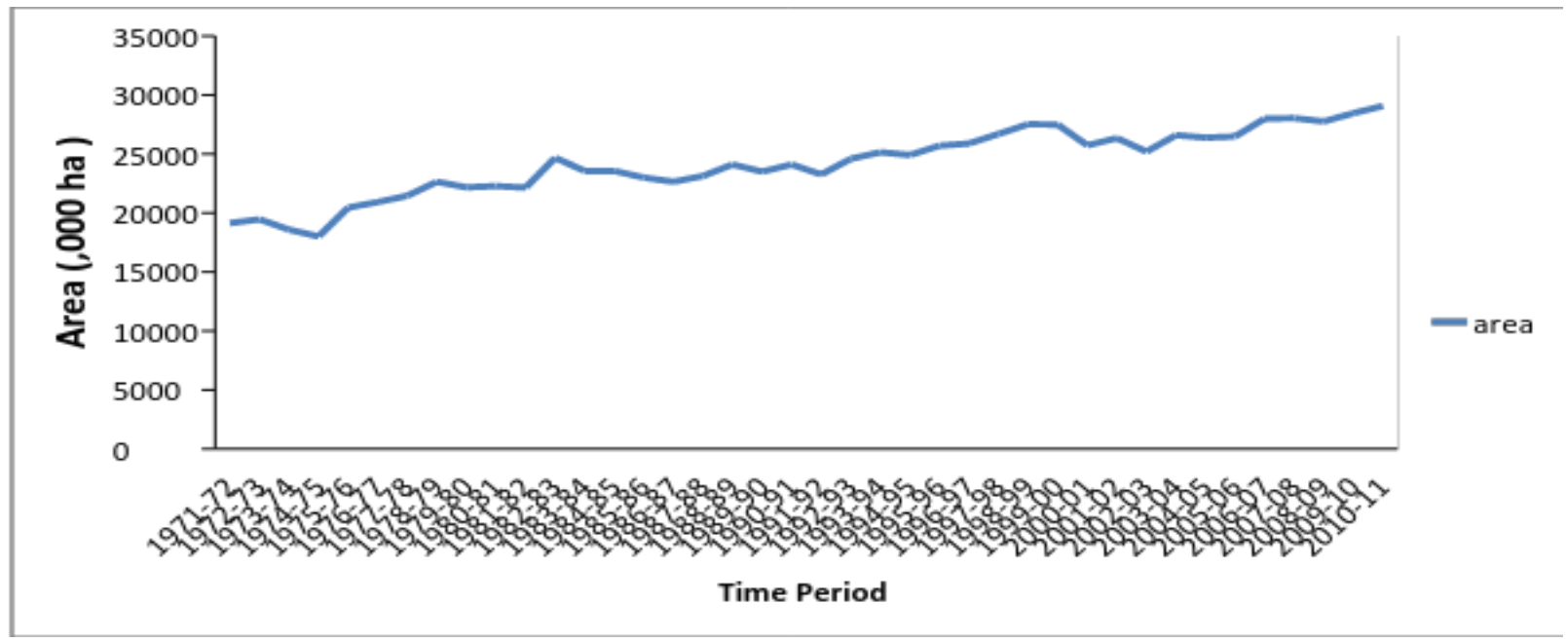

Fig.5 Time series data of total wheat production (Million ton) of India from 1971 to 2010

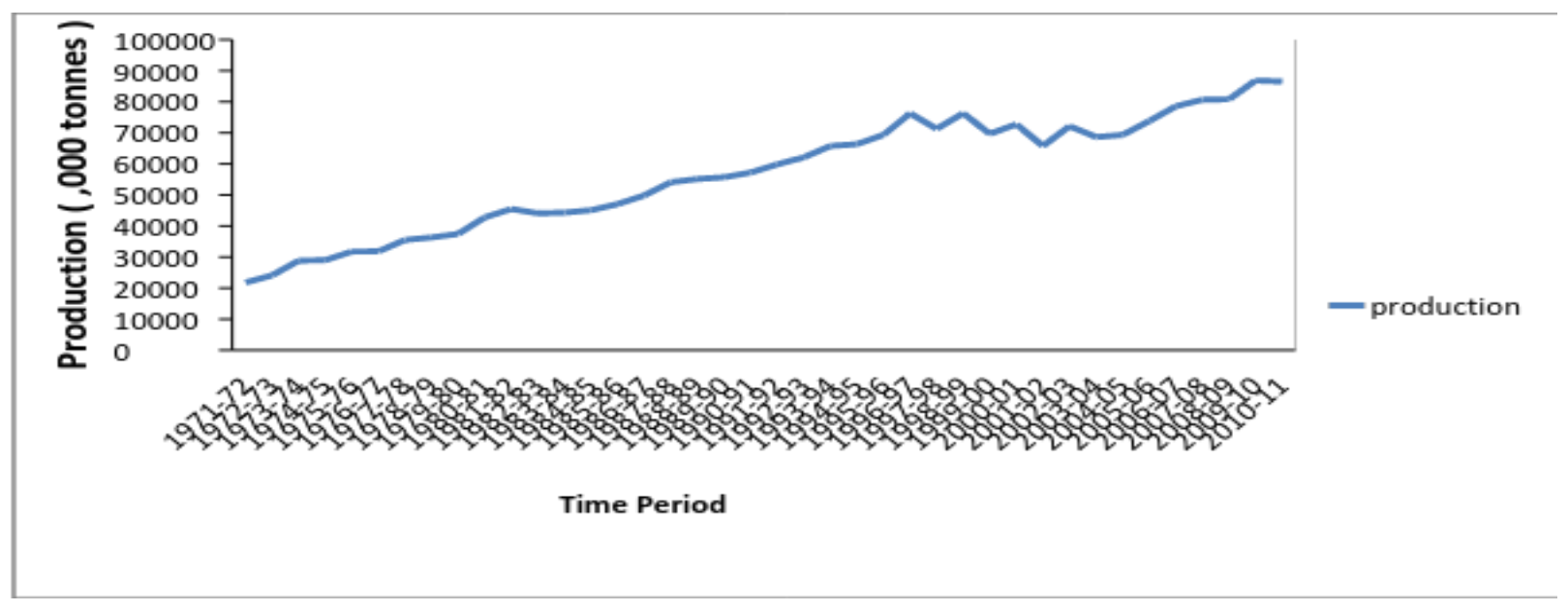

Fig.6 Time series data of total wheat productivity (Kg/ha) of India from 1971 to 2010

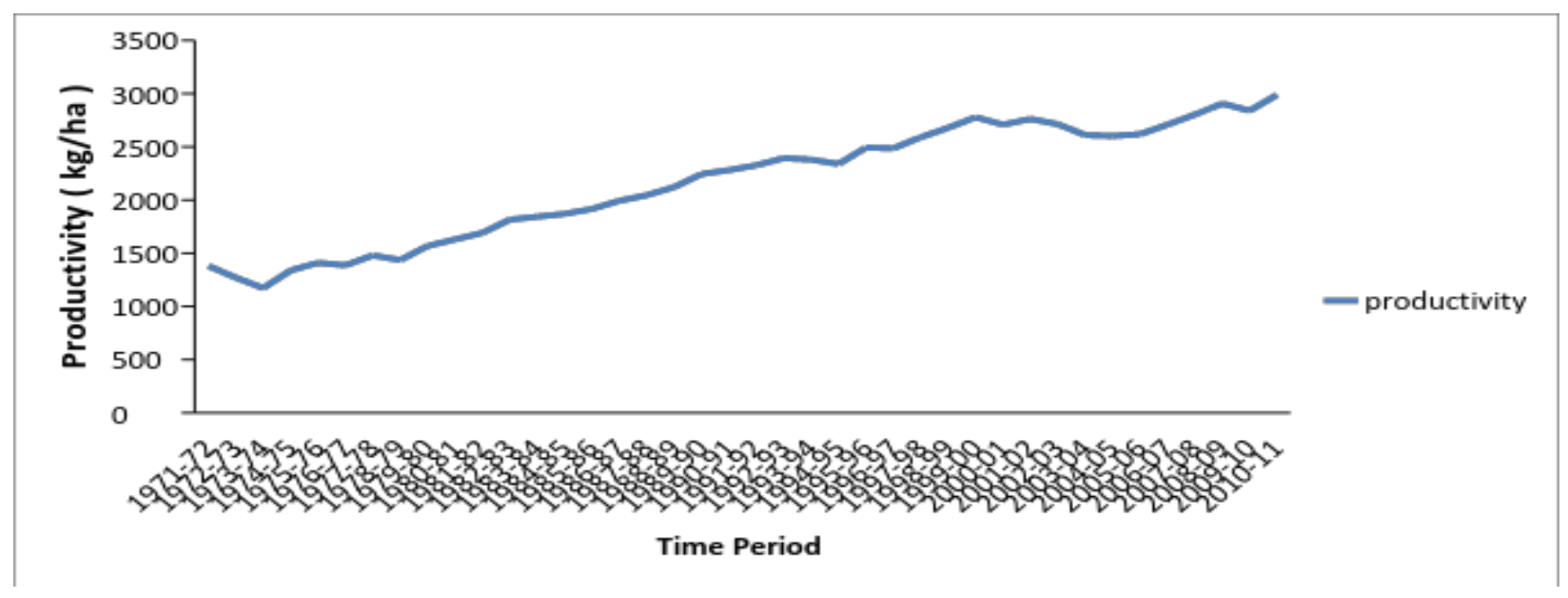


Fitting of different growth models to productivity

The Productivity of Wheat in Uttar Pradesh showed an increasing trend during the study period of 1971 to 2010 . The results obtained by fitting all the ten growth models were presented in Table 7. Adj $\mathrm{R}^{2}$ values for all the models were 0.944 for linear function, 0.834 for logarithmic function, 0.314 for inverse function, 0.905 for quadratic function, 0.904 for cubic function, 0.899 for compound function, 0.854 for power function, 0.387 for S- curve, 0.899 for growth function, and 0.899 for exponential function, respectively. In all the models, Adj $\mathrm{R}^{2}$ values were significant at $1 \%$ level of significance. Linear model was found to be the best for estimation of area of wheat in Uttar Pradesh with higher $\mathrm{Adj}^{2}$ value 0.944 .

\section{Future Projection of area, production and productivity for India and Uttar Pradesh}

There is future projections are also done on the basis of past trend. There is a lot variation in characteristics of future projection of India and Uttar Pradesh. They differ significantly from each other.

The present investigation has been undertaken to evaluate the growth in area, production and productivity of Wheat crop in India and Uttar Pradesh. The linear growth rates and compound growth rates for the study period of 1971 to 2010 were estimated by fitting the linear function and compound function to the area, production and productivity of Wheat crop, respectively.

The average area, production and productivity under Wheat in Uttar Pradesh during the study period were 9.6 million hectares, 30.01 million tonnes and $3113.00 \mathrm{~kg} / \mathrm{ha}$ respectively and exhibited significantly increasing trend with the linear and compound growth rates.

Projections which are made for India and Uttar Pradesh separately giving different information. In India future projection we can see that area is increasing but production is decreasing so it affect the productivity of India. While in case of Uttar Pradesh area, production and productivity is continuously increasing (Tables 8 and 9).

Among the area, production and productivity in Uttar Pradesh, the production exhibited higher growth rates with an increasing trend due to increased trend in growth rates of area and productivity. Among the area, production and productivity, the productivity exhibited higher growth rates with an increasing trend due to increased trend in growth rates of area and productivity. On the basis of the $\operatorname{AdjR}^{2}$ values, cubic model was found to be the best for estimation of area, production and productivity of wheat in India.

\section{References}

Anonymous 2013, publications of Centre for Monitoring Indian Economy (CMIE), Mumbai. India.

Chatterji, A. 1966. A study of agricultural rates during 1950-60 in India. Indian Journal of Agricultural Economics. 20: 20-32.

Singh R.P. (2003) Analysis of growth performance of wheat crop in Jharkhand; Journal of Research, Birsa Agricultural University; 2003.15(2): 217-223.5 ref.

Singh, I.J., Karwasra, K.N and Rai, J.C. 1997. Regional variations in agricultural performance in India. Indian Journal of Agricultural Economics. 52(3): 374-386.

Yoginder Alagh, K and Sharma, P.S. 1980. Growth rates of crop production 1960-61 to 1978-79 is it decelerating? Indian Journal of Agricultural Economics. 35 (2): 104-118.

\section{How to cite this article:}

Manvendra Singh and Supriya, K. 2017. Growth Models and Projection of Area, Production and Productivity of Wheat in India and Uttar Pradesh, India. Int.J.Curr.Microbiol.App.Sci. 6(11): 25872595. doi: https://doi.org/10.20546/ijcmas.2017.611.303 